\title{
Níveis séricos pré-operatórios dos marcadores CEA e CA19-9 e imunoexpressão tecidual do marcador CA19-9 no carcinoma colorretal: relação com os aspectos morfológicos da neoplasia
}

\section{Pre-operative sera levels of CEA and CA19-9 and tissular distribution of tumor marker CA19-9 in colorectal carcinoma: correlation with morphological features of neoplasia}

José Roberto Martins de Souza ${ }^{1}$; José Eduardo Gonçalves ${ }^{1}$; Leandro luongo Matos ${ }^{2}$; Ana Maria Amaral Antonio Mader ${ }^{3}$; Vera Luiza Capelozzl'; Jaques Waisberg, TCBC-SP1

\section{RES U M O}

\begin{abstract}
Objetivo: Comparar os níveis séricos de CA19-9 e CEA e a expressão tecidual do CA19-9 e relacioná-los com os aspectos morfológicos do carcinoma colorretal. Métodos: Quarenta e cinco pacientes com carcinoma colorretal foram operados com coleta de CEA e CA19-9 séricos pré-operatórios. Valores séricos de $C E A=5,0 \mathrm{ng} / \mathrm{mL}$ e de $C A 19-9=37 \mathrm{Ul} / \mathrm{mL}$ foram considerados aumentados. A avaliação da imunoexpressão do CA19-9 no tecido neoplásico foi realizada por meio de estudo imunoistoquímico com anticorpo monoclonal anti-CA19-9. A intensidade de expressão do CA19-9 no tecido neoplásico foi semiquantificada em leve(+/ $+++)$, moderada(++/+++), intensa(+++/+++) e ausente. Resultados: Os valores do CA19-9 sérico foram progressivamente maiores conforme o aumento da expressão do CA19-9 no tecido neoplásico, porém sem significância $(p=0,06)$. O aumento do nível sérico do CA19-9 foi acompanhado de elevação significante $(p<0,001)$ do nível sérico do CEA. O nível sérico do CA19-9, a imunoexpressão tecidual do CA19-9 e o nível sérico do CEA não apresentaram associação significante com características morfológicas do carcinoma colorretal. Conclusão: As expressões sérica e tissular do CA19-9 demonstraram relação diretamente proporcional entre si, enquanto que os aspectos morfológicos da neoplasia não tiveram influência no CEA e CA19-9 séricos ou na imunoexpressão do CA19-9 tissular.
\end{abstract}

Descritores: Carcinoma. Neoplasias colorretais. Marcadores biológicos.

\section{INTRODUÇÃO}

Nosentas os países ocidentais, inclusive no Brasil, o carcinoma colorretal é uma das neoplasias mais frequentes do trato gastrointestinal. É considerado o $3^{\circ}$ carcinoma mais frequente no mundo e o $2^{\circ}$ em países desenvolvidos ${ }^{1-3}$.

O estadiamento da neoplasia colorretal é, ainda, o fator prognóstico mais consistente ${ }^{4,5}$, porém tal informação não é, habitualmente disponível no pré-operatório.

Para a tomada de decisão de se submeter ou não o doente operado de carcinoma colorretal à quimioterapia pós-operatória, é necessário selecionar os enfermos com prognóstico desfavorável, especialmente aqueles com lesões avançadas, e nesse particular, os marcadores tumorais séricos podem ser instrumentos úteis para este propósito.

Devido sua baixa sensibilidade, os marcadores tumorais séricos não são utilizados para diagnóstico precoce e para a realização de varredura (screening) neoplásica ${ }^{6}$, e são utilizados, principalmente, para monitorização do doente após o tratamento indicado - cirúrgico ou não -, e para o diagnóstico precoce da recidiva da neoplasia. Mesmo nos enfermos submetidos à ressecção da doença primária com intenção curativa, a recidiva neoplásica pósoperatória é frequente causa de óbito ${ }^{7,8}$.

O antígeno CA19-9, identificado por Koprowski et al. ${ }^{9}$, é um dos marcadores mais utilizados no carcinoma colorretal. Esse antígeno carboidratado citosólico é uma lacto-N-fucopentose sializada, proteína da família das mucinas, relacionada com o antígeno monosializado do grupo sanguíneo Lewisa que se expressa sobre a membrana celular e no citosol do carcinoma colorretal humano. É sintetizado normalmente pelas células dos ductos pancreáticos e pelos epitélios cólico, gástrico, da vesícula biliar, endometrial e salivar ${ }^{10,11}$. Salces et al. ${ }^{11}$ sugeriram a utilidade do nível sérico do CA19-9 para avaliar o grau de progressão da neoplasia, a radicalidade da operação ou a detecção da sua recidiva. 
Os antígenos de carboidrato associados com tumor são formados em associação com processo de glicolização encontrado essencialmente em todas as células neoplásicas. Os tumores que expressam níveis elevados de determinados tipos de antígenos de carboidrato tumorassociado apresentam maior incidência de metástases e de estádios mais avançados do que as neoplasias que expressam níveis mais baixos, o que se reflete em índices de sobrevivência também menores ${ }^{12}$. O CA19-9 tecidual foi associado à maior incidência de acometimento linfonodal, invasão linfática ${ }^{(13)}$ e metástases ${ }^{14}$.

Os objetivos desse estudo foram investigar a relação entre o nível sérico pré-operatório do CA19-9 com os do CEA e com a distribuição tecidual do CA19-9 em doentes com carcinoma colorretal, correlacionando-os com os aspectos morfológicos da neoplasia.

\section{MÉTODOS}

No período de outubro de 2006 a janeiro de 2008 foram estudados 45 doentes com carcinoma colorretal operados com intenção curativa ou paliativa no Serviço de Gastroenterologia Cirúrgica do Hospital do Servidor Público Estadual de São Paulo - Francisco Morato de Oliveira. Neste estudo, aprovado pelo Comitê de Ética em Pesquisa do IAMSPE, foram considerados critérios de inclusão a presença de carcinoma colorretal confirmada pela análise histopatológica da lesão extirpada com intenção curativa ou de modo paliativo. Foram excluídos pacientes menores de 18 anos. O termo intenção curativa foi definido como todo paciente sem sinais clínicos e radiológicos de doença avançada no estadiamento pré-operatório. O termo paliativo foi utilizado para designar procedimentos em que se constatou a presença de lesão neoplásica residual macro ou microscópica.

A média de idade dos doentes estudados foi de $69,53 \pm 12,37$ anos (41 - 101 anos), sendo $23(51,1 \%)$ do sexo masculino e $22(48,9 \%)$ do sexo feminino.

O estadiamento foi realizado pelo exame clínico e proctológico completos, determinação sérica do CEA e do CA19-9, colonoscopia com biópsia da lesão colorretal e respectivo estudo histopatológico, enema opaco quando indicado, radiografia do tórax, tomografia computadorizada de abdome e ultra-sonografia abdominal.

Para a coleta do CEA e do CA19-9 séricos, todos os enfermos foram submetidos à punção da veia cefálica do membro não dominante imediatamente antes do início da operação. As amostras de sangue foram encaminhadas de forma imediata para mensuração dos níveis séricos de CEA e CA19-9. Adotou-se o nível de corte (cut-off) para o CEA de $=5,0 \mathrm{ng} / \mathrm{mL}$ e para o CA19-9 de $=37 \mathrm{Ul} / \mathrm{mL}$.

Para a realização do estudo histopatológico todos os espécimes cirúrgicos, previamente fixados em solução de formol a 10\%, foram incluídos em blocos de parafina. Três cortes de $4 \mathrm{~mm}$ foram obtidos de cada bloco na periferia do tumor, para obtenção de áreas com e sem tumor, sendo corados pela técnica de hematoxilina-eosina
(HE) para diagnóstico anatomopatológico e avaliação do grau de invasão da parede cólica e do grau de diferenciação celular. A verificação de comprometimento neoplásico dos linfonodos ressecados foi realizada por meio de cortes corados por HE.

Para a realização do estudo imunoistoquímico, todos os espécimes previamente fixados em formol e incluídos em blocos de parafina foram submetidos a dois cortes adicionais de $4 \mathrm{~mm}$ depositados em lâminas previamente silanizadas. As lâminas foram desparafinadas por três banhos sucessivos de cinco minutos de xilol e três banhos em etanol absoluto. A seguir, foram acondicionadas em recipiente próprio e submersas em solução tampão fosfato de sódio $0,05 \mathrm{M}$ e pH 7,2 (PBS) por 10 minutos. Foi realizado bloqueio das peroxidases endógenas pelo gotejamento de peróxido de hidrogênio $30 \mathrm{~V}$ a 3\%, em câmara úmida a temperatura ambiente durante 10 minutos, seguido de mais uma lavagem com PBS por 10 minutos. Terminada esta etapa, realizou-se recuperação antigênica. As lâminas foram acondicionadas em cuba com solução de citrato $10 \mathrm{mM}$, pH 6,0 e submetidas ao calor em banho-maria em temperatura de $35^{\circ} \mathrm{C}$ por período de 40 minutos e, ao final deste processo, foram deixadas esfriar por 20 minutos em temperatura ambiente, sendo realizada lavagem com PBS por cinco minutos. As lâminas foram coradas por meio da técnica imunoistoquímica com anticorpo monoclonal antiCA19-9.

Foi utilizado o complexo estreptavidina-biotinaperoxidase $(A B C)$ adaptado às nossas condições laboratoriais. As lâminas foram incubadas com anticorpo específico antiCA19-9 (GI-MA®, clone L2KGI2, Siemens Healthcare Diagnostics Products Ltd., United Kingdom) diluído em albumina bovina (Sigma $®$ ) durante 16 a 18 horas a $4^{\circ} \mathrm{C}$. Em seguida, foram lavadas em tampão PBS, com três trocas de três a cinco minutos, e incubadas com anticorpo secundário biotinilado (anti-IG) (Dako®) diluído em albumina bovina durante 30 minutos a temperatura ambiente. Seguiram-se as etapas: lavagem em tampão PBS com três trocas de cinco minutos cada; incubação com o complexo $A B C$ (®StretABC-HRP) diluído em tampão Tris, durante 30 minutos à temperatura ambiente; lavagem em tampão PBS com três trocas de três a cinco minutos cada; revelação com solução de diaminobenzidina (DAB) (®Sigma) 0,6\%, peróxido de hidrogênio $\left(\mathrm{H}_{2} \mathrm{O}_{2}\right) 0,06 \%$. As lâminas foram lavadas em água corrente e água destilada, e contra-coradas com hematoxilina de Harris por um minuto, e novamente lavadas em água corrente e água destilada.

O processo final de desidratação das lâminas obedeceu às seguintes passagens: etanol $80 \%$, etanol $90 \%$, etanol absoluto, xilol 1, xilol 2 e xilol 3. Após o processo de imunocoloração as lâminas foram montadas com lamínula e resina.

A leitura de todas as lâminas foi sempre realizada de modo conjunto por dois patologistas experimentados na interpretação imunoistoquímica. A reação foi considerada positiva quando a expressão ocorreu de modo difuso, com distribuição homogênea. A intensidade de expressão do CA19-9 nas áreas neoplásicas foi semi-quantificada em 
cada área de diferenciação tumoral em leve $(+/+++)$, moderada $(++/+++)$, intensa $(+++/+++)$ e ausente. Áreas de diferentes graus de diferenciação celular foram avaliadas em varredura, sempre que presentes nas lâminas (figuras $1 \mathrm{a}$ e $1 \mathrm{~b})$.

As variáveis consideradas para análise estatística foram idade, sexo, localização, diâmetro, presença de invasão vascular linfática e/ou venosa, presença de acometimento linfonodal, presença de infiltração neural, grau de diferenciação celular, profundidade de invasão na parede intestinal, presença de metástases sincrônicas, estadiamento TNM, recidiva, níveis séricos de CA19-9 e CEA e imunoexpressão do CA19-9 tecido do carcinoma colorretal.

O nível de significância adotado foi de 5\% ( $p=$ $0,05)$. Foram realizados cálculos paramétricos e não paramétricos, de acordo com a natureza das variáveis e o $\mathrm{N}$ de cada grupo estudado.

Os modelos estatísticos foram: média aritmética e respectivo desvio-padrão, porcentuais, teste t de Student, teste de Mann-Whitney, teste exato de Fisher, análise de variância (Anova), segundo um critério de classificação e cálculo de concordância e discordância. O programa estatístico utilizado foi: SPSS for Windows 16.0 (SPSS Inc., USA).

\section{RESULTADOS}

Os valores médios séricos do CEA sérico e do CA19-9 foram, respectivamente, de 51,6 $241,4 \mathrm{ng} / \mathrm{mL}$ e $120,5 \pm 440,6 \mathrm{UI} / \mathrm{mL}$. O CEA sérico estava elevado em 15 $(33,3 \%)$ doentes com carcinoma colorretal e o CA19-9 sérico em 10 (22,2\%). Oito (17,7\%) doentes apresentaram elevação de ambos marcadores. Os doentes com elevação do CA19-9 sérico apresentaram correlação significante $(p<0,001)$ com a elevação do CEA sérico.

Em relação à imunoexpressão do CA19-9 no tecido neoplásico colorretal, cinco $(11,1 \%)$ doentes apresentavam imunoexpressão ausente e os valores médios do CEA e do CA19-9 foram, respectivamente, 3,8 $2,6 \mathrm{ng} / \mathrm{mL}$ e $2,8 \pm 2,9 \mathrm{Ul} / \mathrm{mL} ; 12(26,7 \%)$ doentes tinham imunoexpressão leve e os valores médios do CEA e do CA19-9 foram, respectivamente, $2,8 \pm 2,9 \mathrm{ng} / \mathrm{mL}$ e $11,1 \pm 11,1 \mathrm{Ul} / \mathrm{mL} ; 17(37,8 \%)$ doentes exibiam imunoexpressão moderada e os valores médios do CEA e do CA19-9 foram, respectivamente, $102,1 \pm 381,1 \mathrm{ng} / \mathrm{mL}$ e $167,3 \pm 584,1 \mathrm{Ul} / \mathrm{mL} ; 11$ (24,4\%) doentes tinham imunoexpressão intensa e os valores médios do CEA e do CA19-9 foram, respectivamente, $48,4 \pm 125,6 \mathrm{ng} / \mathrm{mL}$ e $221,0 \pm 521,6 \mathrm{Ul} / \mathrm{mL}$. Todos os doentes com imunoexpressão do CA19-9 tecidual ausente apresentavam níveis normais de CA19-9 sérico. A imunoexpressão tecidual do CA19-9 no carcinoma colorretal apresentou tendência $(p=0,06)$ de aumento de sua intensidade conforme ocorreu aumento do seu nível sérico. Dos 45 doentes, em $29(64,4 \%)$ a neoplasia estava localizada no cólon dois no ceco, sete no cólon ascendente, dois no cólon transverso, dois no cólon descendente, 14 no sigmóide -, além de dois doentes com neoplasia sincrônica, uma delas envolvendo sigmóide e cólon transverso e outra envolvendo sigmóide e cólon ascendente. Em 16 (35,6\%) enfermos, a neoplasia estava localizada no reto.

Foi realizada neoadjuvância com radioterapia e quimioterapia (radioterapia de 5040cGy em 28 frações de 180cGy e quimioterapia com 5-fluoracil $1000 \mathrm{mg} / \mathrm{m}^{2} / \mathrm{dia}$ nos primeiros cinco dias e nos últimos cinco dias da radioterapia) em quatro doentes com lesão localizada no reto médio ou baixo.

O nível sérico do CA19-9, o nível sérico do CEA e a imunoexpressão tecidual do CA19-9 não apresentaram relação com as variáveis diâmetro da lesão, acometimento linfonodal, invasão vascular sanguínea e/ou linfática, infiltração neural, grau de diferenciação celular e presença de metástases sincrônicas (Tabelas 1 a 3).

O nível do CEA sérico apresentou tendência de aumento de seus valores com o estadiamento TNM mais avançado, porém não foi significante $(p=0,058)$. O nível do CA19-9 sérico não apresentou relação com o estadiamento TNM $(p=0,90)$. A comparação da imunoexpressão tecidual do CA19-9 no tecido neoplásico classificada como ausente/leve ou moderada/intensa com o estadiamento TNM não foi significante $(p=0,45)$.
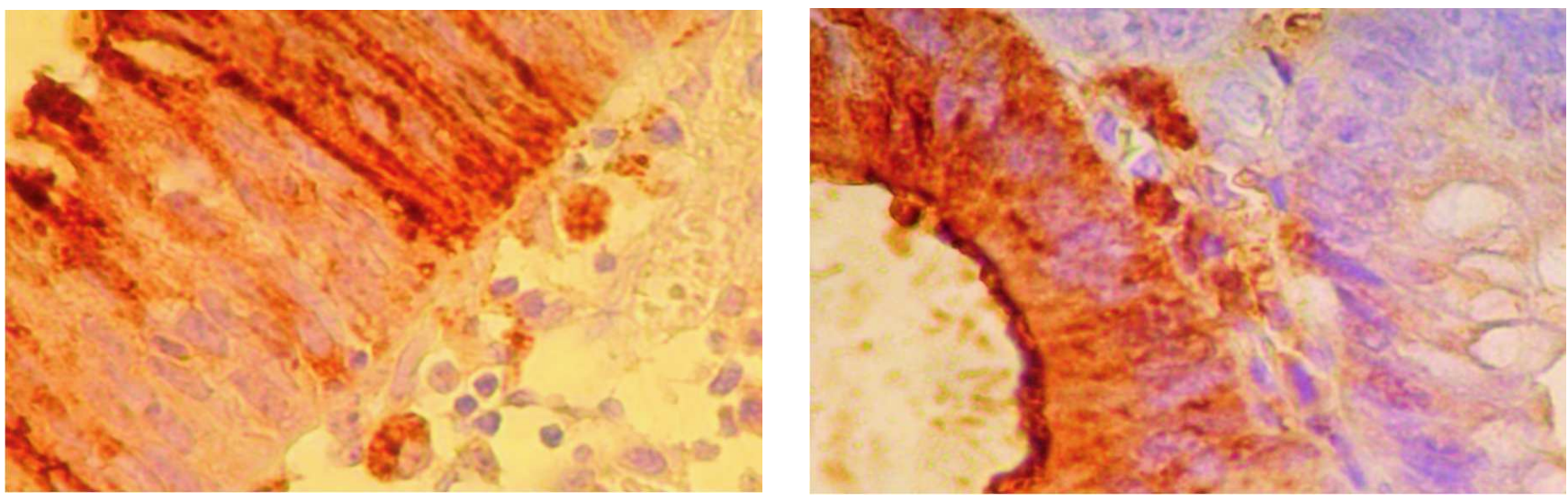

Figura 1 - A - Fotomicrografia de imunoexpressão positiva representada pelo colorido acastanhado no citoplasma das células neoplásicas do carcinoma colo-retal (imunoistoquímica CA 19-9, 400x). B - Fotomicrografia de imunoexpressão fortemente positiva no citoplasma das células neoplásicas do carcinoma colorretal da transição carcinoma-mucosa adjacente e fracamente positiva na mucosa adjacente (imunoistoquímica CA 19-9, 400x). 
Souza

Níveis séricos pré-operatórios dos marcadores CEA e CA19-9 e imunoexpressão tecidual do marcador CA19-9 no carcinoma colorretal: relação com os aspectos morfológicos da neoplasia

Tabela 1 - Valores do CEA sérico comparado com variáveis biodemográficas e morfológicas em doentes operados de carcinoma colorretal.

\begin{tabular}{|c|c|c|c|c|c|}
\hline & $\mathrm{CEA}<5,0 \mathrm{ng} / \mathrm{mL}$ & $(\mathrm{N}=30)$ & $\mathrm{CEA}>5,0 \mathrm{ng} / \mathrm{mL}$ & $(\mathrm{N}=15)$ & $p=$ \\
\hline Idade & $71,53+13,12$ anos & & $65,53+9,93$ anos & & $0,12633 \mathrm{~ns}$ \\
\hline Sexo & $M=16(53,3 \%)$ & $\mathrm{F}=14(46,7 \%)$ & $M=7(46,7 \%)$ & $F=8(53,3 \%)$ & $0,75753 \mathrm{~ns}$ \\
\hline Local & Cólon=20 (66,7\%) & Reto=10 (33,3\%) & Cólon=9 (60,0\%) & Reto $=6(40,0 \%)$ & $0,74630 \mathrm{~ns}$ \\
\hline Diâmetro & $<5 \mathrm{~cm}=20(66,7 \%)$ & $>5 \mathrm{~cm}=10(33,3 \%)$ & $<5 \mathrm{~cm}=8(53,3 \%)$ & $>5 \mathrm{~cm}=7(46,7 \%)$ & $0,51667 \mathrm{~ns}$ \\
\hline Neoadjuvância & $\mathrm{N}=27(90,0 \%)$ & $S=3(10,0 \%)$ & $\mathrm{N}=14(93,3 \%)$ & $S=1(6,7 \%)$ & 0,99999 ns \\
\hline \multicolumn{6}{|l|}{ Linfonodos } \\
\hline Alinfonodos Acometidos & $\mathrm{N}=18(60,0 \%)$ & $S=12(40,0 \%)$ & $\mathrm{N}=5(33,3 \%)$ & $S=10$ & $0,12045 \mathrm{~ns}$ \\
\hline Invasão Vascular Sanguínea & $\mathrm{N}=24(80,0 \%)$ & $S=6(20,0 \%)$ & $\mathrm{N}=9(60,0 \%)$ & $S=6(40,0 \%)$ & $0,17360 \mathrm{~ns}$ \\
\hline Invasão Vascular Linfática & $\mathrm{N}=22(73,3 \%)$ & $S=8(26,7 \%)$ & $\mathrm{N}=7(46,7 \%)$ & $S=8(53,3 \%)$ & 0,10452 ns \\
\hline Invasão Neural & $\mathrm{N}=26(86,7 \%)$ & $S=4(13,3 \%)$ & $\mathrm{N}=11(73,3 \%)$ & $S=4(26,7 \%)$ & $0,40995 \mathrm{~ns}$ \\
\hline Grau de Diferenciação Celular & $1 / P=2(6,7 \%)$ & $M / B=28(93,3 \%)$ & $\mathrm{l} / \mathrm{P}=0(0,0 \%)$ & $M / B=15(100,0 \%)$ & $0,54545 \mathrm{~ns}$ \\
\hline Profundidade de Invasão de Parede & $\mathrm{T} 1 / \mathrm{T} 2=10(33,3 \%)$ & T3/T4=20 (66,7\%) & $\mathrm{T} 1 / \mathrm{T} 2=2(13,3 \%)$ & $\mathrm{T} 3 / \mathrm{T} 4=13(86,7 \%)$ & 0,28329 ns \\
\hline Metástase & $N=29(96,7 \%)$ & $S=1(3,3 \%)$ & $N=10(66,7 \%)$ & $S=5(33,3 \%)$ & 0,01168 * \\
\hline CEA Sérico & $2,04+1,20 \mathrm{ng} / \mathrm{ml}$ & & $150,77+409,20 \mathrm{ng} / \mathrm{r}$ & & $0,05026 \mathrm{~ns}$ \\
\hline CA 19-9 Sérico & $15,11+24,25 \mathrm{UI}$ & & $331,39+733,17 \mathrm{UI}$ & & 0,02140 * \\
\hline CA 19-9 Dicotomizado & $<37 \mathrm{Ul}=28(93,3 \%)$ & $>37 \mathrm{UI}=2(6,7 \%)$ & $<37$ Ul=7 (46,7\%) & $>37 \mathrm{Ul}=8(53,3 \%)$ & 0,00093 * \\
\hline Tecido Dicotomizado & $0 /+=14(46,7 \%)$ & $++/+++=16(53,3 \%)$ & $0 /+=3(20,0 \%)$ & $++/+++=12(80,0 \%)$ & $0,10973 \mathrm{~ns}$ \\
\hline
\end{tabular}

UI: unidades internacionais; ns: não significante; *: significante; M: masculino; F: feminino; N: não; S: sim; I: indiferenciado; P: pouco diferenciado; M: moderadamente diferenciado; B: bem diferenciado; 0: ausência de expressão do CA19-9; +: expressão leve; ++: expressão moderada; +++: expressão intensa.

O tempo médio de acompanhamento dos doentes com carcinoma colorretal foi de 18 $\pm 9,65$ meses ( 1 a 34 meses). Ocorreu recidiva tumoral em 10 (22,2\%) doentes. A recidiva tumoral foi peritoneal em três $(30,0 \%)$ doentes, locorregional em quatro (40,0\%) e hepática em três (30,0\%). O valor médio do CEA sérico foi de $7,8 \pm 15,6 \mathrm{ng} / \mathrm{mL}$ e o CA19-9 sérico foi de $257,1 \pm 763,6 \mathrm{Ul} / \mathrm{mL}$. Nestes doentes, a imunoexpressão do CA19-9 no tecido neoplásico estava ausente em dois $(20,0 \%)$ doentes, leve em dois $(20,0 \%)$, moderada em dois $(20,0 \%)$ e intensa em quatro $(40,0 \%)$.

\section{DISCUSSÃO}

Estudos ${ }^{15-17}$ relataram que a expressão do antígeno CA19-9 em tumores colorretais é indicador útil da

Tabela 2 - Valores do CA19-9 sérico comparado com variáveis biodemográficas e morfológicas em doentes operados de carcinoma colorretal.

\begin{tabular}{|c|c|c|c|c|c|}
\hline & CA $19-9<37$ UI & $(\mathrm{N}=35)$ & CA $19-9$ > 37UI & $(\mathrm{N}=10)$ & $p=$ \\
\hline Idade & $68,77+13,05$ anos & & $72,20+9,68$ anos & & $0,44575 \mathrm{~ns}$ \\
\hline Sexo & $M=19(54,3 \%)$ & $F=16(45,7 \%)$ & $M=4(40,0 \%)$ & $F=6(60,0 \%)$ & $0,49077 \mathrm{~ns}$ \\
\hline Local & Cólon=23 $(65,7 \%)$ & Reto $=12(34,3 \%)$ & Cólon=6 (60,0\%) & Reto $=4(40,0 \%)$ & $0,72592 \mathrm{~ns}$ \\
\hline Diâmetro & $22(62,9 \%)$ & $13(37,1 \%)$ & $5(60,0 \%)$ & $4(40,0 \%)$ & $0,99978 \mathrm{~ns}$ \\
\hline Neoadjuvância & $N=31(88,6 \%)$ & $S=4(11,4 \%)$ & $N=10(100,0 \%)$ & $S=0(0,0 \%)$ & $0,56072 \mathrm{~ns}$ \\
\hline Linfonodos Acometidos & & $5,7 \%)$ & & $0 \%)$ & $0,49077 \mathrm{~ns}$ \\
\hline Invasão Vascular Sanguínea & $\mathrm{N}=27(77,1 \%)$ & $S=8(22,9 \%)$ & \%) & $0 \%)$ & $0,41815 \mathrm{~ns}$ \\
\hline Invasão Vascular Linfática & $N=24(68,6 \%)$ & $S=11(31,4 \%)$ & & $0 \%)$ & 0,45502 ns \\
\hline Invasão Neural & $N=31$ & $4 \%)$ & & $S=4$ & $0,05926 \mathrm{~ns}$ \\
\hline de Diferenciação Celular & $\mid / P=1$ & $(97,1 \%)$ & $\%)$ & $90,0 \%)$ & 0,39899 ns \\
\hline Profundidade de Invasão de Parede & $\mathrm{T} 1 / \mathrm{T} 2=10(28,6$ & T3/T4=25 (71,4\%) & $\mathrm{T} 1 / \mathrm{T} 2=2(20,0 \%)$ & $=8(80,0 \%)$ & $0,70539 \mathrm{~ns}$ \\
\hline Metástase & $\mathrm{N}=31(88,6 \%)$ & $S=4(11,4 \%)$ & $\mathrm{N}=8(80,0 \%)$ & $S=2(20,0 \%)$ & $0,60033 \mathrm{~ns}$ \\
\hline CEA Sérico & $48,85+266,46 \mathrm{ng} / \mathrm{mL}$ & & $61,27+129,19 \mathrm{ng} / \mathrm{m}$ & & $0,88791 \mathrm{~ns}$ \\
\hline CEA Dicotomizado & $<5,0=28(80,0 \%)$ & $>5,0=7(20,0 \%)$ & $<5,0=2(20,0 \%)$ & $>5,0=8(80,0 \%)$ & 0,00093 * \\
\hline CA 19-9 Sérico & $10,22+7,66 \mathrm{UI}$ & & 506,66 + 857,90UI & & 0,00101 * \\
\hline Tecido Dicotomizado & $0 /+=16(45,7 \%)$ & $++/+++=19(54,3 \%)$ & $0 /+=1(10,0 \%)$ & $++/+++=9(90,0 \%)$ & 0,06399 ns \\
\hline
\end{tabular}

UI: unidades internacionais; ns: não significante; *: significante; M: masculino; F: feminino; N: não; S: sim; I: indiferenciado; P: pouco diferenciado; M: moderadamente diferenciado; B: bem diferenciado; 0: ausência de expressão do CA19-9; +: expressão leve; ++: expressão moderada; +++: expressão intensa. 
Tabela 3 - Imunoexpressão do CA19-9 no tecido com neoplasia colorretal comparado com variáveis biodemográficas e morfológicas em doentes operados de carcinoma colorretal.

\begin{tabular}{|c|c|c|c|c|c|}
\hline & \multicolumn{2}{|c|}{ CA 19-9 Tecidual $(0 /+)(N=17)$} & \multicolumn{2}{|c|}{ CA 19-9 Tecidual $(++/+++)(\mathrm{N}=28)$} & $p=$ \\
\hline Idade & $69,71+11,90$ anos & & $69,43+12,45$ anos & & 86 ns \\
\hline Sexo & $M=9(52,9 \%)$ & $\mathrm{F}=8(47,1 \%)$ & $M=14(50,0 \%)$ & $\mathrm{F}=14\left(50,0^{\circ}\right.$ & $0,99999 \mathrm{~ns}$ \\
\hline Local & $1(64,7 \%)$ & Reto= & $18(64,3 \%)$ & Reto $=10(35,7 \%)$ & $0,99999 \mathrm{~ns}$ \\
\hline Diâmetro & $<5 \mathrm{~cm}=11(64,7 \%)$ & $>5 \mathrm{~cm}=6(35,3 \%)$ & $<5 \mathrm{~cm}=17(60,7 \%)$ & $>5 \mathrm{~cm}=11(39,3 \%)$ & $0,99999 \mathrm{~ns}$ \\
\hline Neoadjuvância & & & & & 99 ns \\
\hline Linfonodos Acor & $\mathrm{N}=6$ & $S=11$ & $0,7 \%)$ & & 94 ns \\
\hline nguínea & & & & & $78 \mathrm{~ns}$ \\
\hline Vascular Linfática & $\mathrm{N}=$ & $S=$ & \%) & & 0,7 \\
\hline Neural & & & & & 96 ns \\
\hline Grau de Diferen & $1 / P=$ & $M / B=$ & & $\mathrm{M} /$ & 0,9 \\
\hline Profundidade de Invasão de Parede & $\mathrm{T} 1 / \mathrm{T}$ & $\mathrm{T} 3 / \mathrm{T}$ & $\mathrm{T} 1$ & $\%)$ & $0,4 \varepsilon$ \\
\hline Metástase & $N=15(88,2 \%)$ & $S=2(11,8 \%)$ & $\mathrm{N}=24(85,7 \%)$ & $S=4(14,3 \%)$ & 0,99 \\
\hline CEA Sérico & $3,12+2,79 \mathrm{ng} / \mathrm{mL}$ & & $81,05+304,36 \mathrm{ng} / \mathrm{m}$ & & $0,29918 \mathrm{~ns}$ \\
\hline CEA Dicotomizado & $<5=14(82,4 \%)$ & $>5=3(17,6 \%)$ & $<5=16(57,1 \%)$ & $>5=12(42,9 \%)$ & $0,10973 \mathrm{~ns}$ \\
\hline CA 19-9 Sérico & $8,72+10,10 \mathrm{UI}$ & & $188,43+551,08 \mathrm{UI}$ & & $0,18783 \mathrm{~ns}$ \\
\hline CA 19-9 Dicotomizado & $<37=16(94,1 \%)$ & $>37=1(5,9 \%)$ & $<37=19(67,9 \%)$ & $>37=9(32,1 \%)$ & $0,06399 \mathrm{~ns}$ \\
\hline
\end{tabular}

0: ausência de expressão do CA19-9; +: expressão leve; ++: expressão moderada; +++: expressão intensa; UI: unidades internacionais; ns: não significante; *: significante; M: masculino; F: feminino; N: não; S: sim; I: indiferenciado; P: pouco diferenciado; M: moderadamente diferenciado; B: bem diferenciado.

agressividade da neoplasia e do prognóstico dos doentes. A perda da capacidade das células tumorais para sintetizar ou liberar o CA19-9 pode ser uma explicação para níveis variáveis de CA19-9 no tecido. Outras possíveis explicações incluem a distribuição irregular das lesões e presença de vastas áreas necróticas dentro dos tumore ${ }^{(11}$. Por outro lado, Arends et al. ${ }^{18}$ e Nakagoe et al ${ }^{19}$ relataram que a presença do CA19-9 tecidual nos carcinomas gastrointestinais não está relacionada com os parâmetros de importância prognóstica. A relação entre a expressão do CA19-9 tecidual e o comportamento metastático da neoplasia colorretal permanece, ainda, obscura.

Akamine et al. ${ }^{12}$ verificaram que o nível sérico do antígeno CA19-9 aumentou de acordo com a intensidade da expressão imunoistoquímica do CA19-9 no tecido neoplásico colorretal. No presente estudo, o CA19-9 sérico mostrou tendência $(p=0,06)$ de correlação de seus níveis com a intensidade de imunoexpressão do CA19-9 no carcinoma colorretal. Este fato pode sugerir algum grau de facilidade de acesso do CA19-9 produzido pela neoplasia à corrente sanguínea, podendo o marcador alcançar esta via por drenagem venosa e/ou linfática. Da mesma forma, Nakayama et al. ${ }^{13}$ observaram que doentes com imunoexpressão do CA19-9 tecidual ausente não apresentaram níveis séricos elevados de CA19-9, o que também foi observado no presente estudo. Aqui o CA 199 sérico estava aumentado em $10(22,2 \%)$ doentes, resultado semelhante ao encontrado por outros autores ${ }^{20,21}$ ea elevação do CA19-9 sérico apresentou correlação significante com a elevação do nível sérico do CEA.

Nozoe et a ${ }^{22}$ encontrou nas neoplasias de reto, nível sérico mais elevado, porém não significante de CA199. Na atual série, também se encontrou tendência $(p=0,054)$ de valores maiores do CA19-9 sérico nos carcinomas loca- lizados no reto. Esta diferença de níveis séricos do CA19-9 entre o cólon e reto pode ser explicada devido à presença de lesões mais infiltrativas no reto e pelo fato da drenagem retal poder ocorrer pelos sistemas porta e cava inferior e o acesso do marcador à circulação portal permite sua metabolização pelo fígado e a redução de seus níveis circulantes, exceto, provavelmente, na presença de metástases hepáticas produtoras de CA19-9.

Nakayama et al. ${ }^{13}$ e Nakagoe et al.(23) não encontraram relação significante da localização da neoplasia com a imunoexpressão tecidual do CA19-9, resultados concordantes com os do presente estudo.

Existe discordância na literatura a respeito da relação entre os níveis séricos do CA 19-9 e o diâmetro do carcinoma colorretal. Chen et al. ${ }^{24}$ e Sasaki et al. ${ }^{25}$ não encontraram relação do nível sérico do CA19-9 com o diâmetro da lesão colorretal, o que ocorreu também na atual série onde os doentes com carcinomas com diâmetro < $5,0 \mathrm{~cm}$ e $=5,0 \mathrm{~cm}$ tiveram níveis de CA19-9 sérico semeIhantes $(p=0,99)$. Porém, Nakayama et al..$^{13}$ e Nozoe et al. ${ }^{22}$ encontraram níveis significantemente maiores de CA199 sérico em tumores com diâmetro $>5,0 \mathrm{~cm}$.

Em relação à imunoexpressão tecidual do CA199 , este estudo não encontrou relação significante com o diâmetro das lesões colorretais, achado idêntico ao de outros autores ${ }^{17,23}$.

No presente estudo, não foi encontrado relação significante entre o CA19-9 sérico e o acometimento linfonodal, resultado semelhante ao de Sasaki et al. ${ }^{25}$ Por sua vez, Zheng et al. ${ }^{20}$ e Nozoe et al. ${ }^{22}$ encontraram maior acometimento de linfonodos em doentes com CA19-9 sérico elevado.

Nakayama et al. ${ }^{13}$ relataram correlação significante da imunoexpressão tecidual CA19-9 com a pre- 
sença de linfonodos acometidos. No presente estudo, esta relação não foi significante $(p=0,12)$, assim como a da imunoexpressão com a presença de linfonodos acometidos pela neoplasia e a presença de invasão linfática microscópica. Esta divergência nos resultados pode ser devido à diferença entre as casuísticas. Na atual série, a maioria dos doentes não tinha comprometimento linfonodal, o que você ter influenciado o resultado. Estudos ${ }^{13,22,25}$ sugeriram que a presença de invasão vascular angiolinfática não está relacionada com os níveis séricos de CA19-9. O mesmo resultado foi encontrado em relação à imunoexpressão tecidual do CA19-9 neste trabalho, resultado também observado por Nakayama et al. ${ }^{13}$.

O presente estudo encontrou níveis séricos elevados, porém não significantes do CA19-9 na presença de invasão neural em doentes com carcinoma colorretal. Já a imunoexpressão tecidual do CA19-9 foi semelhante nos doentes com ou sem presença de invasão neural. Não foi possível realizar o cotejamento destes achados com o de outros autores devido à pequena quantidade de publicações que avaliaram a invasão neural.

Em relação ao grau de diferenciação celular, Zheng et al. ${ }^{20}$, Chen et al. ${ }^{(24)}$, Sasaki et al. ${ }^{25}$ e Nozoe et al. ${ }^{22}$ não encontraram diferença significante quando compararam esta variável com os níveis séricos de CA19-9, resultados semelhantes aos aqui apresentados.

A imunoexpressão do CA19-9 também não mostrou relação significante com o grau de diferenciação celular, o que também foi relatado por Nakayama et al. ${ }^{13}$.

A literatura é divergente em relação aos resultados entre o nível sérico de CA19-9 e a profundidade de invasão de parede. Nakayama et al. ${ }^{13}$ e Zheng et al. ${ }^{20}$ encontraram valores significantemente elevados de CA19-9 sérico conforme a maior profundidade de invasão da parede colorretal, o que não foi observado por Nozoe et al. ${ }^{22} \mathrm{e}$ pelo presente estudo.

Nakayama et al. ${ }^{13}$ não encontraram relação significante entre a profundidade de invasão visceral e o grau de imunoexpressão tecidual do CA19-9, resultado semelhante ao verificado na atual série. Estes resultados podem ser considerados conflitantes, uma vez que há tendência de ocorrer maiores níveis séricos de marcadores tumorais conforme aumenta a profundidade de invasão e o tamanho da massa tumoral ${ }^{26}$. Nesta csuística, a maioria dos doentes (67\%) foi classificada como T3/T4 e nenhum T1, ou seja, uma amostra provavelmente adequada de doentes para avaliar a profundidade de invasão e seria esperado valores séricos de CA19-9 e imunoexpressão tecidual do CA19-9 mais expressivos, porém este fato não ocorreu.

No tocante à classificação TNM, este estudo não obteve correlação com os níveis séricos de CA19-9, resultado semelhante ao encontrado por Chen et al. ${ }^{24}$, Zheng et al. ${ }^{20}$ e Nozoe et al. ${ }^{22}$, por sua vez encontraram relação significante dos níveis séricos do CA19-9 e do CEA com o estadiamento mais avançado na classificação de Dukes.

No presente estudo, comparando-se a imunoexpressão tecidual do CA19-9 no tecido neoplásico classificada como ausente/leve ou moderada/intensa, não se encontrou resultados significantes. Por outro lado, Morales-Gutiérrez et al. ${ }^{27}$ mostraram que a imunoexpressão tecidual do CA19-9 tecidual aumenta progressivamente conforme o estadiamento de Dukes torna-se mais avançado. Na atual série, $48,8 \%$ dos doentes foram classificados como estágios I/II, ou seja, estágios considerados não avançados e apenas $13,3 \%$ dos doentes em estágio IV, o que pode ter influenciado os resultados.

Na presente série, o tempo médio de acompanhamento pós-operatório foi de 18 meses ( 1 a 34 meses) e $22,2 \%$ dos doentes apresentaram recidiva do carcinoma colorretal neste período. Nakayama et al. ${ }^{13}$ e Zheng et al. ${ }^{20}$ encontraram recidivas significantemente maiores em doentes com níveis séricos pré-operatórios elevados de CA199. Nakayama et al. ${ }^{13}$ encontraram ainda, relação significante entre o CA19-9 sérico pré-operatório e a imunoexpressão tecidual do CA19-9 com a recidiva da neoplasia, principalmente a hematogênica. Nakagoe et al. ${ }^{19}$ relataram que a elevação pré-operatória no nível sérico de CA19-9 era preditor independente da recidiva do tumor dos doentes com carcinoma colorretal, mesmo sem comprometimento linfonodal e que tinham sido tratados com ressecção curativa. Morales-Gutiérrez et al. ${ }^{27}$ sugeriram que a recidiva do carcinoma colorretal é significantemente maior nas neoplasias de reto e a probabilidade de recidiva aumenta progressivamente com a maior intensidade de imunoexpressão tecidual do CA19-9.

Takada et al. ${ }^{28}$ relataram que o antígeno CA199 serve como ligante específico para a molécula de adesão endotelial de leucócito (ELAM-1), o que pode ajudar as células tumorais na adesão às células circulantes e, consequentemente, iniciar o processo metastático. O antígeno CA19-9 pode estar envolvido no processo de angiogênese tumoral influenciando o rápido crescimento do tumor e das metástases. Esta pode ser uma das razões principais devido a qual os casos com níveis séricos mais elevados de CA19-9 mostraram frequência maior de metástases e, consequentemente, pior prognóstico ${ }^{29}$. Nakagoe et al. ${ }^{23}$ relataram que o CA19-9 sérico é fortemente associado à metástases à distância. No presente estudo, não se constatou relação do CA19-9 sérico e da imunoexpressão do CA19-9 tecidual com a incidência de metástases. Seguindo o raciocínio que conforme aumenta a profundidade de invasão e o tamanho da massa, aumentam os níveis séricos dos marcadores tumorais ${ }^{26}$, é esperado que neoplasias em estágios mais avançados tenham maiores chances de recidiva e metástases, já que são consideradas doenças sistêmicas.

Estudo conduzido por Shimono et al. ${ }^{16}$ utilizou o método imunoistoquímico para determinar a imunoexpressão do CA19-9 em 149 pacientes com câncer colorretal primário. Oitenta e seis (56\%) tumores marcaram positivamente, e 22 (15\%) revelaram teste padrão fortemente expressado. Nestes casos, o CA19-9 não foi somente marcado nas áreas apicais e citoplasmáticas de células do tumor, mas igualmente no estroma. Constatou-se que os doentes com CA19-9 acentuadamente expressado sobrevivem significantemente menos do que aqueles com 
o marcador negativo ou marcado somente na área apical das células do tumor. Por outro lado, Nakagoe et al. ${ }^{23}$ não encontraram diferença significante de sobrevivência em relação à imunoexpressão tecidual do CA19-9.

No tocante à imunoexpressão do tecido neoplásico do CA19-9, a detecção e quantificação de um marcador com diferentes reagentes podem não produzir resultados idênticos, mesmo que estes reagentes sejam utilizados em formatos similares do ensaio. Teste específico para marcador individual, mesmo se realizado de forma uniforme, pode ser interpretado de maneira diferente com a utilização de diferentes sistemas de análise de sinal. Vários métodos de escore de imunocoloração foram propostos. A mesma lâmina pode ser lida por microscopia de luz com a interpretação humana ou por computador. Poderse-ia considerar apenas coloração nuclear e ignorar todos os outros padrões de coloração (por exemplo, citosólicas ou membrana) ou vice-versa. Em algumas escalas, considera-se apenas que as células são positivas ou negativas. Em outras, a intensidade de coloração está consignada com a percentagem de células positivas coradas por imunoistoquímica para criar índice ou escore. A comparação de resultados entre estas duas análises separadas poderia conduzir a conclusões bastante diferentes ${ }^{30}$.

O significado clínico e biológico do marcador detectado em associação com uma célula (por exemplo, no citosol ou membrana) pode ser muito diferente do que o do mesmo marcador quando é visto como um fator solúvel em fluidos. Os resultados obtidos a partir de biópsia por aspiração por agulha podem ser diferentes daqueles utilizando a mesma análise de células idênticas coletadas em amostra de biópsia de maiores dimensões, na qual a ar- quitetura do tecido é preservada. Diferentes estratégias de modelos de preparação e armazenamento das amostras podem alterar radicalmente os resultados do ensaio. Muitos ensaios de marcador tumoral - especialmente aqueles que são baseadas em reações antígeno-anticorpo -, são muito mais sensíveis em espécimes frescos ou congelados. Em tecidos fixados, a "sobrevivência" do antígeno pode variar de acordo com os diferentes fixadores. Os ensaios podem ser influenciados não só pelo fixador ou tipos de anticoagulantes utilizados na preparação da lâmina, mas também pelas condições de armazenamento, bem como pela duração do armazenamento. Para muitos marcadores solúveis, ciclos de congelamento e descongelamento múltiplos podem diminuir a reatividade das células, dependendo do ensaio específico. Mesmo que os métodos de coleta e armazenamento sejam padronizados, as diferenças de amostragem podem alterar substancialmente os resulta$\operatorname{dos}^{30}$.

O presente estudo encontrou aumento progressivo do grau de imunoexpressão tecidual do CA19-9 conforme ocorreu aumento dos níveis séricos do CA19-9, porém não significante. O nível sérico do CA19-9 e a imunoexpressão tecidual do CA19-9 não apresentaram relação com as variáveis morfológicas do carcinoma colorretal. É possível que a intensidade de imunoexpressão tecidual do CA19-9 possa predizer pior prognóstico em doentes com estadiamento não avançado (estádios I e II) e sugerir a realização de tratamento rádio e quimioterápico mais agressivo. Julga-se ser importante a padronização do estudo imunoistoquímico e da leitura da imunoexpressão tecidual do marcador CA19-9 para esclarecer-se o papel biológico do marcador CA 19-9 no carcinoma colorretal.

\title{
A B S T R A C T
}

\begin{abstract}
Objective: To compare sera levels of CEA and CA19-9 and tissular expression of the CA19-9 and to correlate these with morphological features of the colorectal carcinoma. Methods: Forty five patients with colorectal carcinoma underwent surgical treatment following measurement of pre-operative levels of CA19-9 and CEA. Sera levels of CEA = 5.0ng/ml and CA19-9 = 37UI were deemed high values. Evaluation of CA19-9 immunoexpression in neoplastic tissue was carried through by means of immunohistochemical study with monoclonal antibody anti-CA19-9. The intensity of expression of CA19-9 in neoplastic areas was semi-quantified in each area of tumor differentiation into mild(+/+++), moderate $(++/+++)$, intense $(+++/++)$ or absent. Results: Sera CA19-9 values were progressively higher in the presence of elevated CA19-9 immunoexpression in colorectal carcinoma tissue, although not significant $(p=0.06)$. Increased sera CA19-9 levels were found to be associated with significantly elevated $(p<0.001)$ sera CEA levels. Levels of sera CA19-9, tissular immunoexpression of CA19-9 and sera levels of CEA presented no significant association with morphological features of the colorectal carcinoma. Conclusion: Sera and tissular levels of the CA19-9 marker exhibited, each other, a directly proportional relationship. The morphological features of the neoplasia had no influence on sera CEA or CA19-9 levels or tissular immunoexpression of CA19-9.
\end{abstract}

Key words: Carcinoma. Colorectal Neoplasias. Biologicals Markers.

\section{REFERÊNCIAS}

1. Instituto Nacional de Câncer. Coordenação de Prevenção e Vigilância de Câncer. Estimativas 2008: incidência de câncer no Brasil. Rio de Janeiro: INCA; 2007

2. Jantscheff P, Terraciano L, Lowy A, Glatz-Krieger K, Grunert F, Micheel $B$ et al. Expression of CEACAM6 in resectable colorectal cancer: a factor of independent prognostic significance. J Clin Oncol. 2003; 21(19):3638-46.

3. Levy M, Visokai V, Lipska L, Topolcan O. Tumor markers in stanging and prognosis of colorectal carcinoma. Neoplasma. 2008; 55(2):138-42.

4. Wiggers T, Arends JW, Volovics A. Regression analysis of prognostic factors in colorectal cancer after curative resections. Dis Colon Rectum. 1988; 31(1):33-41. 
5. Ponz de Leon M, Sant M, Micheli A, Sacchetti C, Di Gregorio C, Fante $\mathrm{R}$ et al. Clinical and pathologic prognostic indicators in colorectal cancer. A population-based study. Cancer. 1992; 69(3):626-35.

6. Duffy MJ, van Dalen A, Haglund C, Hansson L, Holinski-Feder E, Klapdor $\mathrm{R}$ et al. Tumour markers in colorectal cancer: European Group on Tumour Markers (EGTM) guidelines for clinical use. Eur J Cancer. 2007: 43(9):1348-60.

7. Daniels IR, Fisher SE, Heald RJ Moran BJ. Accurate staging, selective preoperative therapy and optimal surgery improves outcome in rectal cancer: a review of the recent evidence. Colorectal Dis. 2007; 9(4):290-301.

8. Stein U, Schlag PM. Clinical biological and molecular aspects of metastasis in colorectal cancer. Recent Results Cancer Res. 2007; 176:61-80.

9. Koprowski H, Steplewski Z, Mitchell K, Herlyn M, Herlyn D, Fuhrer P. Colorectal carcinoma antigens detected by hybridoma antibodies. Somatic Cell Genet. 1979; 5(6):957-72.

10. Carpelan-Holmström $M$, Louhimo J, Stenman UH, Alfthan $H_{\text {, }}$ Järvinen $\mathrm{H}$, Haglund $\mathrm{C}$. Estimating the probability of cancer with several tumor markers in patients with colorectal disease. Oncology. 2004; 66(4):296-302.

11. Salces I, Vegh I, Rodriguez-Muñoz S, Colina F, Pérez A, Soto $S$ et al. Tissue CA19-9 content in colorectal adenomas and its value in the assessment of dysplasia. Rev Esp Enferm Dig. 2004; 96(4):246-54.

12. Akamine $S$, Nakagoe $T$, Sawai T, Tsuji T, Tanaka k, Hidaka $S$ et al. Differences in prognosis of colorectal cancer patients based on the expression of sialyl Lewis ${ }^{\mathrm{a}}$, sialyl Lewis ${ }^{\mathrm{x}}$, and sialyl Lewis ${ }^{\mathrm{Tn}}$ antigens in serum and tumor tissue. Anticancer Res. 2004; 24(4):2541-6.

13. Nakayama T, Watanabe M, Teramoto T, Kitajima M. CA19-9 as a predictor of recurrence in patients with colorectal cancer. J Surg Oncol. 1997; 66(4):238-43.

14. Matsui $T$, Kojima $H$, Susuki $H$, Hamajima $H$, Nakazato $H$, Ito $K$, Nakao A, Sakamoto J. Sialyl Lewis ${ }^{a}$ expression as a predictor of the prognosis of colon carcinoma patients in a prospective randomized clinical Trial. Jpn J Clin Oncol. 2004; 34(10):588-93.

15. Asai S, Watanabe T, Sakamoto J, Kiriyama K, Ito K, Akiyama S, Takagi $\mathrm{H}$. [Expression and prognostic indicators of type 1 and type 2 Lewis blood group antigens in colorectal cancers]. Nippon Geka Gakkai Zasshi. 1994; 95(10):753-62.

16. Shimono R, Mori M, Akazawa K, Adachi $Y$, Sgimachi K. Immunohistochemical expression of carbohydrate antigen 19-9 in colorectal carcinoma. Am J Gastroenterol. 1994; 89(1):101-5.

17. Nakayama T, Watanabe $M$, Teramoto $T$, Kitajima M. Slope analysis CA19-9 and CEA for predicting recurrence in colorectal cancer patients. Anticancer Res. 1997; 17(2B):1379-82.

18. Arends JW, Schutte B, Wiggers T, Verstijnen CP, Blijham GH, Bosman FT. Comparison of phenotypic and genotypic features in human primary large bowel carcinomas and lymph node metastases. Cancer Res. 1987; 47(16):4342-4.

19. Nakagoe T, Sawai T, Tsuji T, Jibiki MA, Nanashima A, Yamaguchi T et al. Difference in prognostic value between sialyl Lewis(a) and sialyl Lewis $(x)$ antigen levels in the preoperative serum of gastric cancer patients. J Clin Gastroenterol. 2002; 34(4):408-15.

20. Zheng CX, Zhan WH, Zhao JZ, Zheng D, Wang DP, He YL, Zheng $Z Q$. The prognostic value of preoperative serum levels of CEA,
CA19-9 and CA72-4 in patients with colrectal cancer. World J Gastroenterol. 2001; 7(3):431-4

21. Morita S, Nomura T, Fukushima Y, Morimoto T, Hiraoka N, Shibata N. Does serum CA19-9 play a practical role in the management of patients with colorectal cancer? Dis Colon Rectum. 2004; 47(2):227-32.

22. Nozoe T, Rikimaru T, Mori E, Okuyama T, Takahashi I. Increase in both CEA and CA19-9 in sera is an independent prognostic indicator in colorectal carcinoma. J Surg Oncol. 2006; 94(2):132-7.

23. Nakagoe T, Fukushima K, Nanashima A, Sawai T, Tsuji T, Jibiki M et al. Expression of Lewis(a), sialyl Lewis(a), Lewis $(x)$ and sialyl Lewis $(x)$ antigens as prognostic factors in patients with colorectal cancer. Can J Gastroenterol. 2000; 14(9):753-60.

24. Chen CC, Yang SH, Lin JK, Lin TC, Chen WS, Jiang JK, Wang HS, Chang SC. Is it reasonable to add preoperative serum level of CEA and CA19-9 to staging for colorectal cancer? J Surg Res. 2005; 124(2):169-74.

25. Sasaki A, Kawano K, Inomata M, Shibata K, Matsumoto T, Kitano S. Value of serum carbohydrate antigen 19-9 for predicting extrahepatic metastasis in patients with liver metastasis from colorectal carcinoma. Hepatogastroenterology. 2005; 52(66):1814-9.

26. Coelho JC. Aparelho Digestivo: clínica e cirurgia. $3^{a}$ ed. São Paulo: Atheneu; 2005.

27. Morales-Gutiérrez C, Vegh I, Colina F, Gómez-Cámara A, Ignacio Landa J, Ballesteros D, Carreira PE, Enríquez-De-Salamanca R. Survival of patients with colorectal carcinoma: possible prognostic value of tissular carbohydrate antigen 19.9 determination. Cancer. 1999; 86(9):1675-81.

28. Takada A, Ohmori K, Yoneda T, Tsuyuoka K, Hasegawa A, Kiso M, Kannagi R. Contribution of carbohydrate antigens sialyl Lewis $A$ and sialyl Lewis $X$ to adhesion of human cancer cells to vascular endothelium. Cancer Res. 1993; 53(2):354-61.

29. Ueda T, Shimada E, Urakawa T. The clinicopathologic features of serum CA 19-9-positive colorectal cancers. Surg Today. 1994: 24(6):518-25

30. Hayes DF, Bast RC, Desch CE, Fritsche H Jr, Kemeny NE, Jessup JM et al. Tumor marker utility grading system: a framework to evaluate clinical utility of tumor markers. J Natl Cancer Inst. 1996; 88(20):1456-66.

Recebido em 20/01/2009

Aceito para publicação em 23/03/2009

Conflito de interesse: nenhum

Fonte de financiamento: nenhuma

\section{Como citar esse artigo:}

Souza JRM, Gonçalves JE, Matos LL, Mader AMAA, Capelozzi VL, Waisberg J. Níveis séricos pré-operatórios dos marcadores CEA e CA199 e imunoexpressão tecidual do marcador CA19-9 no carcinoma colorretal: relação com os aspectos morfológicos da neoplasia. Rev Col Bras Cir. [periódico na Internet] 2010; 37(2). Disponível em URL: http:/ wwww.scielo.br/rcbc

Endereço para correspondência:

José Roberto Martins de Souza

E-mail: joserobertomtsouza@hotmail.com 